\title{
Investigation the Behavior of MODIS Ocean Color Products under the 2008 Red Tide in the Eastern Persian Gulf
}

\author{
M. Ghanea ${ }^{a,}{ }^{*}$, M. Moradi a ${ }^{a}$ K. Kabiri a \\ ${ }^{a}$ Department of Marine Remote Sensing, Iranian National Institute for Oceanography and Atmospheric Science, Tehran, Iran - \\ (m.ghanea, moradi, kabiri)@inio.ac.ir or m.ghanea.ui@gmail.com
}

KEY WORDS: Red Tide, MODIS Ocean Color Product, Chlorophyll- $a$, Normalized Fluorescence Line Height, Diffuse Attenuation Coefficient, the Strait of Hormuz

\begin{abstract}
:
Biophysical properties of water undergo serious variations under red tide (RT) outbreak. During RT conditions, algal blooms spread out in the estuarine, marine and fresh waters due to different triggering factors such as nutrient loading, marine currents, and monsoonal winds. The Persian Gulf (PG) was a talent region subjected to different RTs in recent decade. A massive RT started from the Strait of Hormuz in October 2008 and extended towards the northern parts of the PG covering more than $1200 \mathrm{~km}$ of coastlines. The bloom of microorganism C. Polykrikoides was the main specie that generated large fish mortalities, and hampered marine industries, and water desalination appliances.

Ocean color satellite data have many advantages to monitor and alarm RT occurrences, such as wide and continuous extent, short time of imagery, high accessibility, and appropriate estimation of ocean color parameters. Since 1999, MODerate Resolution Imaging Spectroradiometer (MODIS) satellite sensor has estimated satellite derived chlorophyll-a (Chl-a), normalized fluorescence line height $(\mathrm{nFLH})$, and diffuse attenuation coefficient at $490 \mathrm{~nm}(\mathrm{kd} 490)$. It provides a capability to study the behavior of these parameters during RT and normal conditions.

This study monitors variations in satellite derived Chl-a, nFLH, and kd490 under both RT and normal conditions of the PG between 2002 and 2008. Up to now, daily and monthly variations in these products were no synchronously investigated under RT conditions in the PG. In doing so, the MODIS L1B products were provided from NASA data archive. They were corrected for Rayleigh scattering and gaseous absorption, and atmospheric interference in turbid coastal waters, and then converted to level 2 data. In addition, Enhanced Red Green Blue (ERGB) image was used to illustrate better water variations. ERGB image was built with three normalized leaving water radiance between 443 to $560 \mathrm{~nm}$. All the above data processes were applied by SeaDAS 7 software package. The Strait of Hormuz was selected as the study area in the eastern part of the PG. Images including high cloud coverage $(>50 \%)$ over the study area were filtered out. The classification maps of the above products were shown during RT and normal periods. Monthly variations of mentioned products were calculated for the dates before, during, and after RT appearance. The results were demonstrated as time-series diagrams. All the above calculations and presentations were performed in Matlab 7 software package.
\end{abstract}

The results show that MODIS Chl-a, nFLH, and kd490 increased during the $2008 \mathrm{RT}$. Based on the feedback of these parameters under RT conditions, hybrid ocean color index (HOCI) is defined. HOCI is able to display better water variations during RT outbreak. High values of HOCI show RT affected areas.

\section{INTRODUCTION}

Red tide (RT) is rapidly propagation of algal blooms in the estuarine, marine and fresh waters (Al-Muhairi et al. 2010). Sun light and nutrient loading are triggering factors for phytoplankton growth, which can be spread out by marine currents, dust, and monsoonal winds (Brink et al., 1998; Wiggert et al., 2010; Al-Azri et al., 2010, 2013; Al-Shehhi et al., 2011). RT affects marine life and human health by mortality of great number of fishes and lobsters, disturbance of fishing activities, irritating the eyes, and damage the desalination plants and respiratory systems (Richlen et al., 2010; Al-Shehhi et al., 2011, 2013).

Monitoring RT is significant for environmental, ecological, and biological management of water regions. Using satellite data is a right solution to generate diurnal ocean color products in wide coverage of water regions. MODerate Resolution Imaging Spectroradiometer (MODIS) is a sensor mounted on two satellites Aqua (from 2002) and Terra (from 1999). It has many capabilities to monitor oceanographic phenomena by extracting different ocean color products such as Chlorophyll-a (Chl-a), normalized fluorescence line height (nFLH), and diffuse attenuation coefficient at $490 \mathrm{~nm}\left(\mathrm{~K}_{\mathrm{d}}{ }^{490}\right)$. Earlier research accurately estimated algal biomass by MODIS OC3 algorithm (O'Reilly et al., 1998, Carder et al., 1999, 2004). In addition, MODIS $\mathrm{K}_{\mathrm{d}}{ }^{490}$ accurately estimated Secchi dish depth, as a criterion for water turbidity in the Persian Gulf (PG) (Al-Kaabi et al., 2013). Overpass times in the late morning (at 10:30 by MODIS-Terra) and early afternoon (at 13:30 by MODIS-Aqua) helps researchers to investigate diurnal changes of ocean phenomena (Salomon et al., 2001).

\footnotetext{
${ }^{*}$ Corresponding author.
} 
In recent studies, MODIS Chl- $a$ and nFLH were successful to monitor RT in the PG (Moradi and Kabiri, 2012; Zhao et al., 2014, 2015). However, they are not useful to distinguish harmful algal blooms from non-toxic ones. So, studying the behavior of other satellite-driven products under RT affected areas is necessary to monitor RT better.

In this study, the Strait of Hormuz in the eastern PG is considered as case study. MODIS Chl-a, nFLH, and $\mathrm{K}_{\mathrm{d}}{ }^{490}$ are classified for the dates before and during RT outbreak. We then investigate monthly variations of mentioned products during RT and normal conditions between 2002 and 2008. A hybrid ocean color index (HOCI) is also defined based on the behavior of the above products during the RT occurrence in 2008.

\section{DATA AND METHOD}

\subsection{Case Study}

The PG is a shallow, marginal sea in the south of Iran. It connects to the Oman Sea by the Strait of Hormuz. It is a talent region for RT activities (Thangaraja et al., 2007). Occurrence of harmful algal blooms and death of marine organisms are common in the PG and the Oman Sea (Thangaraja, 1998; ROPME, 2003). Earlier studies have reported 38 taxa in the PG, including 18 ones for the specie level and the others for the genus level (Al-Hassan et al., 1990; Rezai, 1995; Thangaraja et al., 2001). In fall 2008, a wide-spread harmful algal bloom happened in the PG. It started from the Masqat coastlines in the Oman Seas, and expanded most water regions in the PG during several months (Richlen et al., 2010; Moradi and Kabiri, 2012; Zhao et al., 2015).

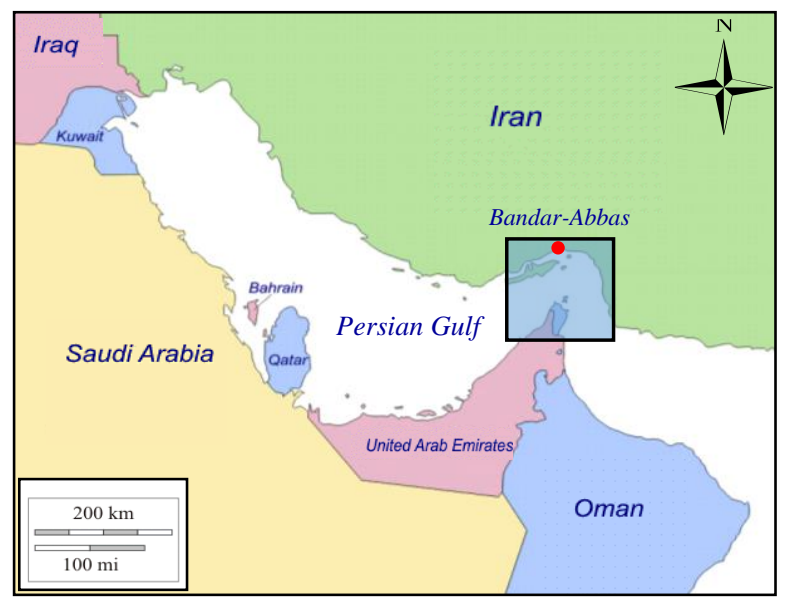

Figure 1. Case study: the Striat of Hormuz

The C. Polykrikoides bloom was often existed in the PG during the RT period (Richlen et al., 2010). It caused many mortalities of fishes and marine mammals (Berktay 2011), extensive damage to coral reefs, and marine industries, including filtrations and desalination plants (WDR, 2008). There has been no clear reason yet to explain the exact mechanism of $C$. Polykrikoides in the PG (Moradi and Kabiri, 2012). Figure 1 shows the Bandare-Abbas offshore in the Strait of Hormuz. This case study is proper to study how development harmful algal blooms developed in 2008.

\subsection{Satellite Data Processing}

MODIS Aqua and Terra level 1A (L1A) data with spatial resolution of $1 \mathrm{~km}$ were downloaded from NASA data archive (http: //ladsweb.nascom. nasa.gov/data) and processed to L2 products using SeaDAS (version 6.4) software package developed by NASA. The flow chart of satellite data processing is shown in Figure 2.

After atmospheric correction and cylindrical projection, L2 products including Chl-a, nFLH, and $\mathrm{K}_{\mathrm{d}}{ }^{490}$ estimated from Mueller (2000), Morel et al. (2007), and Lee et al. (2005) algorithms. Enhanced Red-Green-Blue (ERGB) image was generated with three $\mathrm{L} 2$ normalized water leaving radiance at 547 (R), 488 (G), and 443 (B) nm for MODIS, which have been stretched to the same scale.

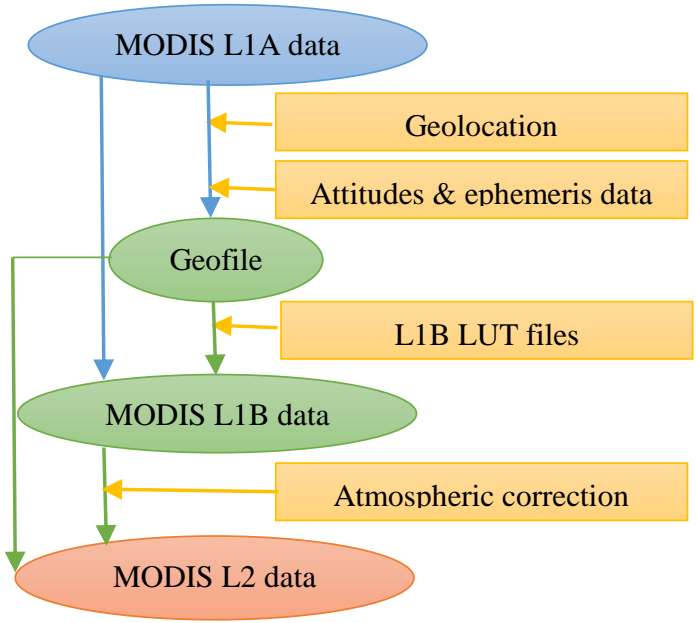

Figure 2. The flow chart of data processing by SeaDAS 6.4

L2 products with high cloud coverage $(>50 \%)$ over the case study were filter out. Figure 4 shows Classification maps of each product to distinguish RT affected areas. Figure 3 demonstrates monthly average value of each product from August to December between 2002 and 2008. Based on the achieved conclusions in the next section, HOCI index is introduced as a new index to better discriminate RT affected areas. All the above procedures were carried out in MATLAB 7 software.

\section{RESULTS AND DISCUSSION}

Due to heavy cloudiness, aerosol, and water vapor conditions, Aqua and Terra do not cover the Strait of Hormuz in some days especially during summer. The values of water vapor and aerosol during summer are usually more than those values in fall. Therefore, the number of days including qualified data in August and September is less than the number of days in October, November, and December (Table 1). The bloomtracking vectors in Figure 4, column 1 show that algal blooms entered the Strait of Hormuz from the north-eastern part on October 14, 2008, and extended towards the south-western part in the next dates (Figure 4, columns 2-4). 


\begin{tabular}{|c|c|c|c|c|c|c|c|}
\hline \multirow[b]{2}{*}{$\stackrel{\Xi}{\tilde{0}}$} & \multicolumn{7}{|c|}{ Year } \\
\hline & ఠి & ఠ్రి & $\underset{\overbrace{}}{\stackrel{\overbrace{}}{8}}$ & ஜ & ஓి & $\widehat{\delta}$ & $\stackrel{\infty}{8}$ \\
\hline 8 & 0 & 1 & 0 & 1 & 1 & 0 & 1 \\
\hline 9 & 3 & 0 & 2 & 4 & 3 & 6 & 1 \\
\hline 10 & 8 & 6 & 2 & 10 & 8 & 14 & 5 \\
\hline 11 & 15 & 15 & 11 & 13 & 11 & 15 & 8 \\
\hline 12 & 13 & 8 & 8 & 14 & 7 & 10 & 14 \\
\hline
\end{tabular}

Table 1 . The number of dates, including qualified satellite data for months 8 to 12 between 2002 and 2008 .

The monthly average values for Chl-a, $\mathrm{K}_{\mathrm{d}}{ }^{490}$, and $\mathrm{nFLH}$ were more than 12, 0.8 , and 0.04 respectively from October to November in 2008. These values were not observed in the normal conditions. The maximum monthly average of Chl-a,
$\mathrm{K}_{\mathrm{d}}{ }^{490}$, and $\mathrm{nFLH}$ occurred during November 2008. After November 19, 2008, the bloom-tracking vector shows that algal blooms were propagated towards the middle Persian Gulf and they disappeared in south-eastern part of the Strait of Hormuz (Figure 4). So, the values of Chl-a, $\mathrm{K}_{\mathrm{d}}{ }^{490}$, and $\mathrm{nFLH}$ were decreased in December 2008 (Figures 3, a-c).

The trendlines in Figure 5 show that nFLH had no correlation with Chl-a and $\mathrm{K}_{\mathrm{d}}{ }^{490}$ in the normal situation. It should be due to low concentrations of algal bloom which caused to reduce flourecense emmision. Instead, high concentrations of algal bloom caused to increase nFLH in the RT period. So it created a near-perfect correlation among nFLH, Chl-a, and $\mathrm{K}_{\mathrm{d}}{ }^{490}$. High correlation $\left(=\mathrm{R}^{2}>0.9\right)$ among these three products is another suitable criterion to find $\mathrm{RT}$ affected areas.

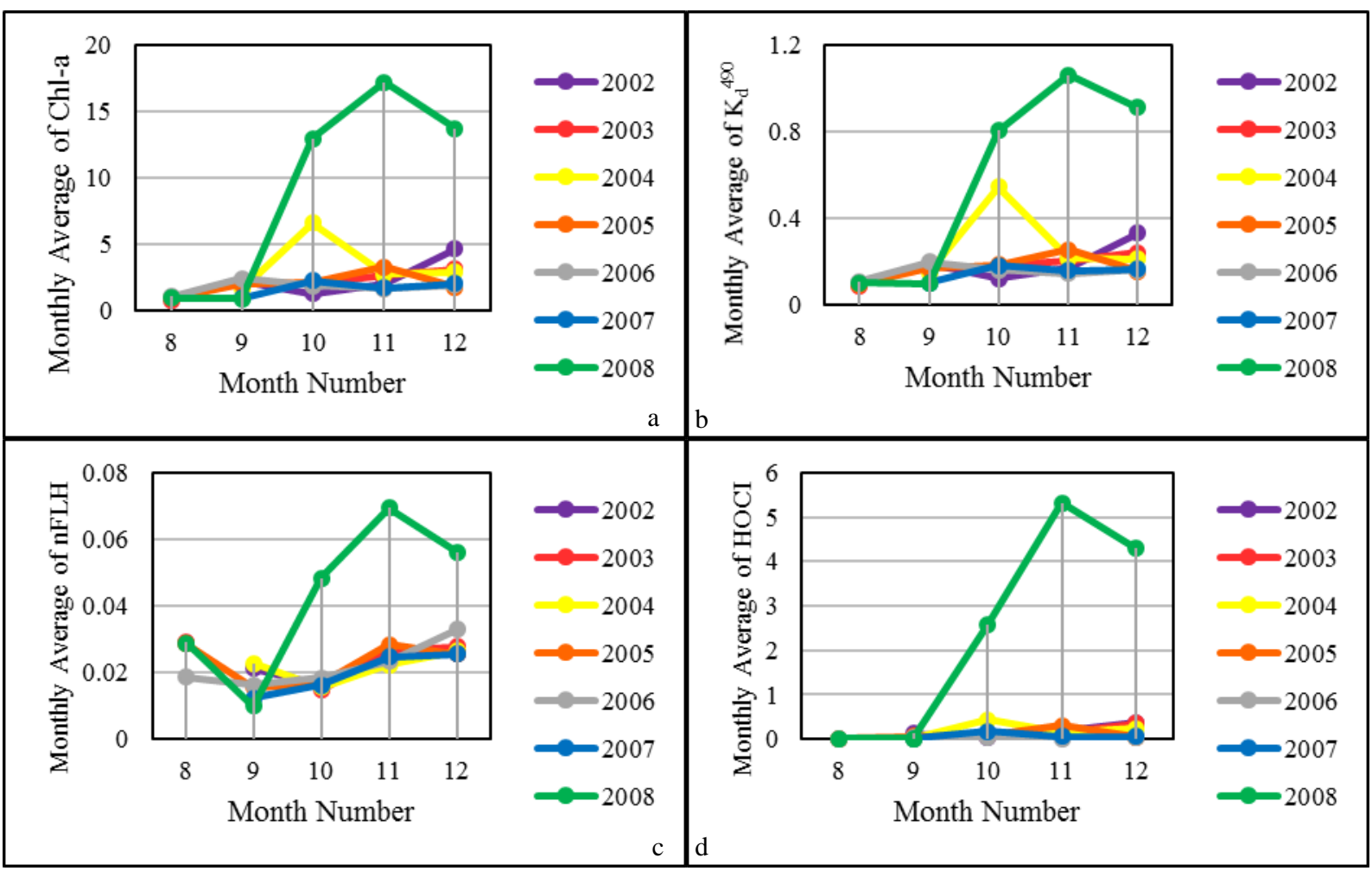

Figure 3. Monthly variations of Chl-a, $\mathrm{K}_{\mathrm{d}}^{490}$, nFLH, and HOCI between 2002 and 2008. Longitude range: 56 20'28'- 56 $34^{\prime} 24^{\prime \prime}$, latitude range: $26^{\circ} 22^{\prime} 51^{\prime \prime}-27^{\circ} 04^{\prime} 36^{\prime \prime}$.

Figure 5,b shows that $\mathrm{K}_{\mathrm{d}}{ }^{490}$ had near-perfect correlation with Chl-a. Hence, phtoplanktons play an important role on water turbidity, especially during the RT period. In contrast, high amounts of suspended sediment and nutrient loading are dominant factors to increase turbidity or $\mathrm{K}_{d}{ }^{490}$ during the normal period.

Figures 5,a and 5,c confirm that nFLH had no increasing response during the normal period. Therefore, it can discriminate RT affected areas better than Chl-a. Moradi and Kabiri (2012) proved that nFLH is a better index than Chl-a. Since color dissolved organic material (CDOM) may be misinterpreted as Chl-a, particularly for case 2 waters where CDOM rather than phytoplankton overcomes blue-light absorption. To the same reason, high CDOM value increases the amounts of Chl-a and $\mathrm{K}_{d}{ }^{490}$ in the normal situation (Figure $5, \mathrm{~b})$.
As a general conclusion, the monthly average of Chl-a, Kd490, and $\mathrm{nFLH}$ had an increasing response to the $2008 \mathrm{RT}$ occurred in the PG. To display a hybrid behaviour of these parameters during the RT period, hybrid ocean color index (HOCI) is defined as follows:

$$
\mathrm{HOCI}=\mathrm{Chl}-\mathrm{a} * \mathrm{~K}_{\mathrm{d}} 490 * \mathrm{nFLH} .
$$

Table 2 classifies variation range of Chl-a, Kd490, nFLH, and HOCI in the RT and normal periods. The units of Chl-a, $\mathrm{K}_{d}{ }^{490}$, $\mathrm{nFLH}$, and HOCI are mg.m $\mathrm{m}^{-3}, \mathrm{~m}^{-1}, \mathrm{~mW} \cdot \mathrm{cm}^{-2} \cdot \mu \mathrm{m}^{-1} \cdot \mathrm{sr}^{-1}$, and $\mathrm{mW} \cdot \mathrm{cm}^{-2} \cdot \mu \mathrm{m}^{-1} \cdot \mathrm{sr}^{-1} \cdot \mathrm{mg} \cdot \mathrm{m}^{-4}$, respectively. 

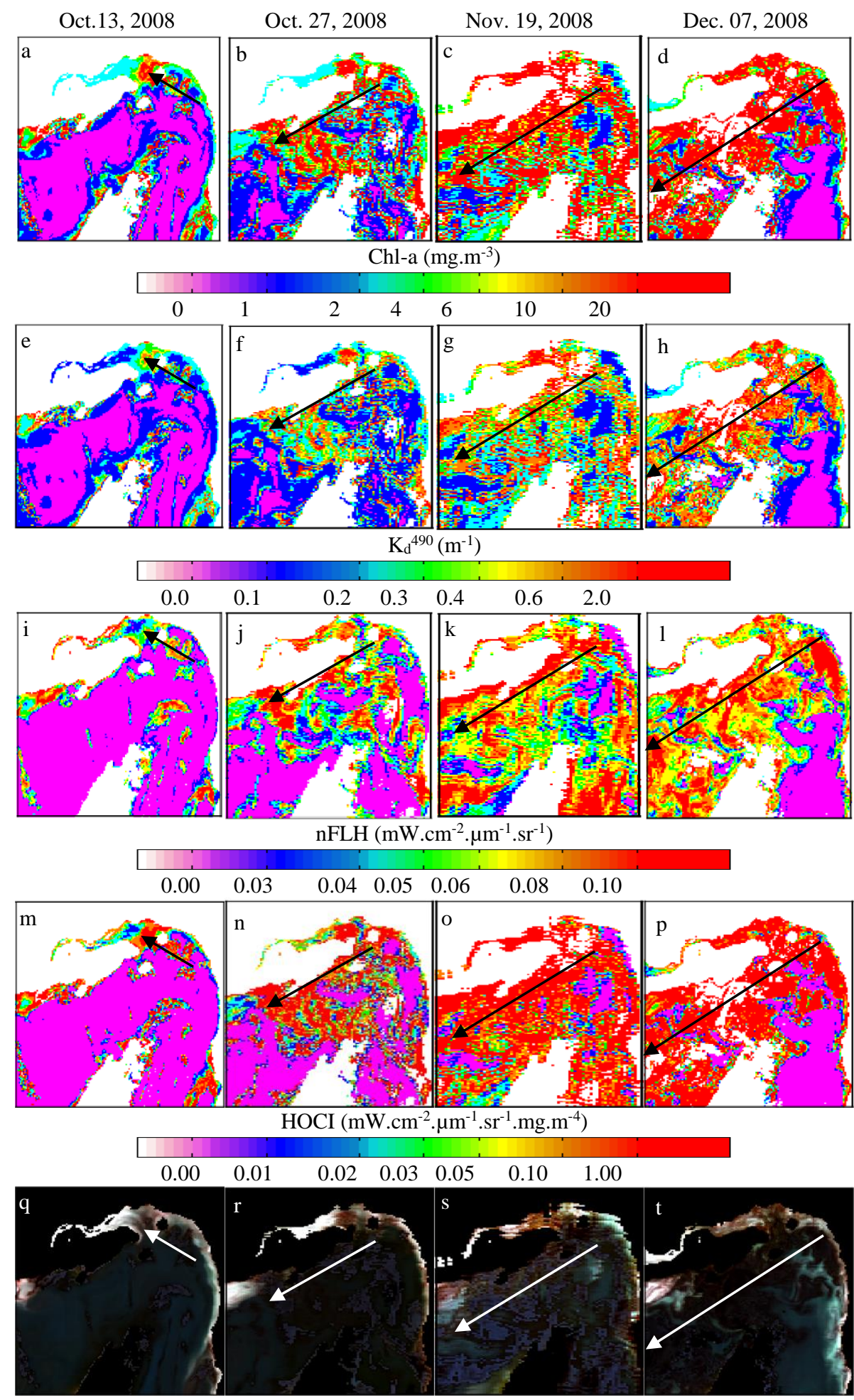

Figure 4. Classification maps of Chl-a, $\mathrm{Kd}_{\mathrm{d}}{ }^{490}, \mathrm{nFLH}$, and $\mathrm{HOCI}$ plus to ERGB images in the Strait of Hormuz during four days from October to November in 2008. Black and white vectors track the path of bloom extension. 
HOCI value was $>2.5$ during the 2008 RT occurance. The maximum value of HOCI during the normal condition (between August, 2002 and September, 2008) was 0.43 (Figure 3,d). The monthly average value of HOCI during the RT period is 5-10 times more than that value in the normal situation. Such difference was not observed for Chl-a, $\mathrm{K}_{d}{ }^{490}$, and $\mathrm{nFLH}$. Consequently, HOCI better discriminates RT affected areas from non-affected ones. In fact, it is a combination of Chl-a, $\mathrm{K}_{\mathrm{d}}^{490}$, and nFLH togetherly. So, RT occurs while the amounts of these three products are high synchronously. This means that high values of Chl-a and $\mathrm{K}_{\mathrm{d}}{ }^{490}$ are not the necessary condition for RT event, e.g. October 2004. In addition, high nFLH value is not enough for RT appearance, e.g. December 2006 (Figure $3)$.

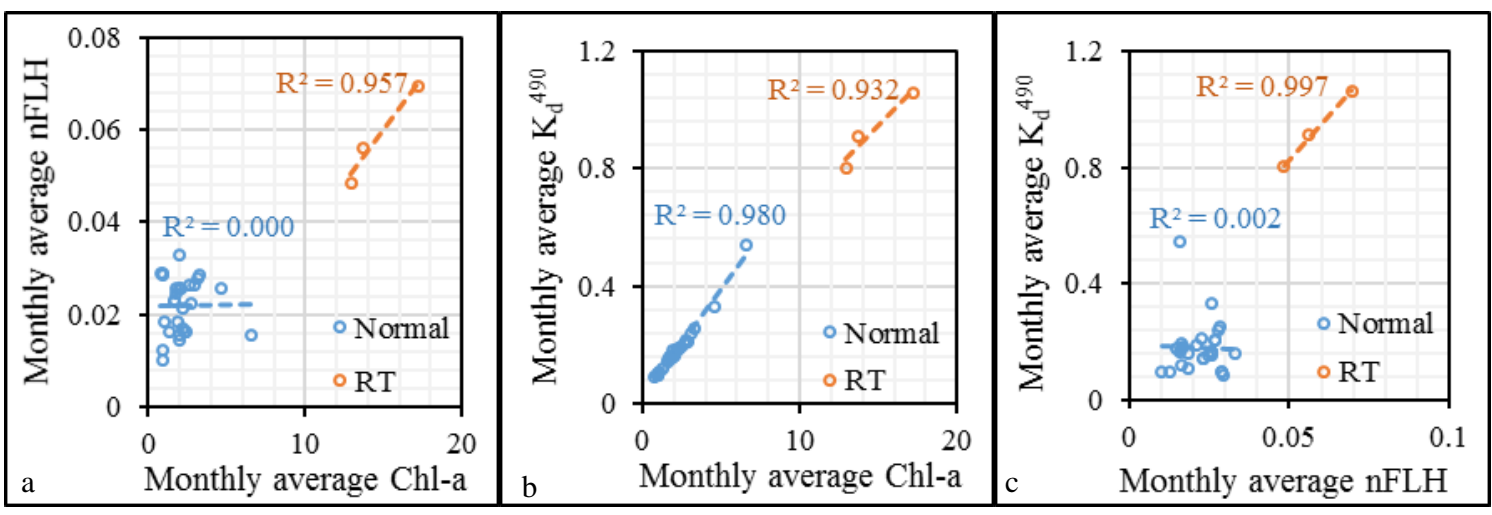

Figure 5. Scatter plots of Chl-a, $\mathrm{K}_{d}{ }^{490}$, and $\mathrm{nFLH}$ vs each other during the normal and RT periods. The units of Chl-a, $\mathrm{K}_{\mathrm{d}}{ }^{490}$, and $\mathrm{nFLH}$ are mg. $\mathrm{m}^{-3}, \mathrm{~m}^{-1}$, and $\mathrm{mW} . \mathrm{cm}^{-2} \cdot \mu \mathrm{m}^{-1} \cdot \mathrm{sr}^{-1}$, respectively. Dashed lines represent trend lines and $\mathrm{R}^{2}$ is coefficient of determination. Longitude range: $56^{\circ} 20^{\prime} 28^{\prime \prime}-56^{\circ} 34^{\prime} 24^{\prime \prime}$, latitude range: $26^{\circ} 22^{\prime} 51^{\prime \prime}-27^{\circ} 04^{\prime} 36^{\prime \prime}$.

HOCI value is $<0.5$ during the normal conditions. This should be due to the low amount of $\mathrm{K}_{\mathrm{d}}^{490}(<0.1)$ or the low turbidity (= high transparency) of water before the RT outbreak. The ERGB images show that water clarity reduced from November 13 , 2008 to December 7, 2008 (Figure 4, q-t). Dark waters in the ERGB images represent high concentrations of algal bloom.

\begin{tabular}{|c|cccc|}
\cline { 2 - 5 } \multicolumn{1}{c|}{} & \multicolumn{4}{c|}{ Product } \\
\hline Period & Chl-a & $\mathrm{K}_{\mathrm{d}}{ }^{490}$ & nFLH & HOCI \\
\hline RT & $>12$ & $>0.8$ & $>0.04$ & $>2.5$ \\
\hline Normal & $<7$ & $<0.6$ & $<0.03$ & $<0.5$ \\
\hline
\end{tabular}

Table 2. The variation ranges of Chl-a, Kd490, nFLH, and $\mathrm{HOCI}$ in the RT and normal periods.

\section{CONCLUSIONS}

This paper investigated the response of three MODIS L2 products under the RT and normal conditions. Besides algal bloom, CDOM and nutrient loading play significant roles in increasing the amounts of Chl-a and $\mathrm{K}_{\mathrm{d}}{ }^{490}$ during the normal period. In the same condition, $\mathrm{nFLH}$ was more sensitive to algal bloom than Chl-a and $\mathrm{K}_{\mathrm{d}}{ }^{490}$. $\mathrm{nFLH}$ value was approximately constant and low alternative in the normal situation. Instead, nFLH had high value and high correlation with Chl-a and $\mathrm{K}_{\mathrm{d}}{ }^{490}$ during the 2008 RT. According to the attributes of three mentioned products, HOCI was defined to better discriminate RT affected areas from non-affected ones. There was a high HOCI difference between the normal and RT periods, while such large difference was not observed for Chl-a, $\mathrm{K}_{\mathrm{d}}{ }^{490}$, and nFLH. Visual matching between high HOCI values and dark features in the ERGB images was more than Chl-a, $\mathrm{K}_{\mathrm{d}}{ }^{490}$, and $\mathrm{nFLH}$. Hence, HOCI is a capable index to monitor RT.

\section{REFERENCES}

Al-Azri, A., Piontkovski,S.A., Al-Hashmi,K., Goes,J., and Gomes, H., 2010. Chlorophyll-a as a measure of seasonal coupling between phytoplankton and the monsoon periods in the Gulf of Oman.Aquatic Ecology, 44, pp. 449-461.

Al-Azri, A. R., Piontkovski, S. A., Al-Hashmi, K. A., Goes, J. I., Gomes, H. d. R., and Glibert, P. M, 2014. Mesoscale and nutrient conditions associated with the massive 2008 Cochlodinium polykrikoides bloom in the Sea of Oman/Arabian Gulf. Estuaries and Coasts, 37(2), pp 325-338.

Al-Hasan, R.H., Ali, A.M. and Radwan, S.S., 1990. Lipids, and their constituent fatty acids, of Phaeocystis sp. from the Arabian Gulf. Marine Biology, 105, pp. 9-14.

Al-Muhairi, A., Ghedira, H., and Shaheen, A., 2010. Combining satellite-derived chlorophyll-a data and highresolution dubaisat-1 data to detect and monitor RT outbreaks in the Arabian Gulf. In: Geoscience and Remote Sensing Symposium, IEEE, pp. 3692-3695.

Al-Shehhi, M.R., Gherboudj, I., Ghedira, H., 2012. A study on the effect of dust and wind on phytoplankton activities in the Arabian Gulf. In: Geosci. Remote Sens. Symp. (IGARSS) IEEE, pp. 2571-2574.

Al-Shehhi, M.R., Gherboudj, I., Zhao, J., Mezhoud, N., and Ghedira, H., 2013. Evaluating the Performance of MODIS FLH Ocean Color Algorithm in Detecting the Harmful Algae Blooms in the Arabian Gulf and the Gulf of Oman. In: IEEE, San Diego, CA, pp. 1-7.

Al-Kaabi, M. R., Zhao, J., Charron, C., Gherboudj, I., Lazzarini, M., and Ghedira, H., 2013. Developing satellitebased tool for water turbidity mapping in the Arabian Gulf: Abu Dhabi case study. In: IEEE, San Diego, CA, pp. 1-4.

Berktay, A., 2011. Environmental approach and influence of red tide to desalination process in the Middle East region. International Journal, 2(3), pp. 183-188.

Brink, K., Arnone, R., Coble, P., Flagg, C., Jones, B., Kindle, J., and Lee, C., 1998. Monsoons boost biological productivity 
in the Arabian Sea. EOS Transactions. American Geophysical Union, 79(13): pp. 168-169.

Carder, K.L., Chen, F.R., Lee, Z.P., Hawes, S.K. and Kamykowski, D., 1999. Semi-analytic Moderate Resolution Imaging Spectrometer algorithms for chlorophyll $a$ and absorption with bio-optical domains based on nitrate-depletion temperatures. Journal of Geophysical Research, 104, pp. 54035422.

Carder, K. L., Chen, F. R., Cannizzaro, J.P., CAMPBELL, J.W. and Mitchell, B.G., 2004. Performance of MODIS SemiAnalytic Ocean Color Algorithm for Chlorophyll-a. Advances in Space Research, 33, pp. 1152-1159.

Moradi, M., and Kabiri, K., 2012. Red tide detection in the Strait of Hormuz (east of the Persian Gulf) using MODIS fluorescence data. International Journal of Remote Sensing, 33(4), pp. 1015-1028.

Mueller, J. L., 2000. SeaWiFS algorithm for the diffuse attenuation coefficient, $\mathrm{K}(490)$, using water-leaving radiances at 490 and $555 \mathrm{~nm}$, in Sea-WiFS Postlaunch Calibration and Validation Analyses, part 3 edited by S. B. Hooker. NASA Goddard Space Flight Cent., Greenbelt, Md, pp. 24-27.

Morel, A., Huot, Y., Gentili, B., Werdell, P. J., Hooker, S. B., and Franz, B. A., 2007. Examining the consistency of products derived from various ocean color sensors in open ocean (Case 1) waters in the perspective of a multi-sensor approach. Remote Sens. Environ., 111(1), pp. 69-88.

Lee, Z. P., Darecki, M., Carder, K. L., Davis, C.O., Stramski, D., and Rhea, W.J., 2005. Diffuse attenuation coefficient of downwelling irradiance: an evaluation of remote sensing methods. Journal of Geophysical Research, 110(C2), pp. 19782012.

O'Reilly, J.E., Maritorena, S., Mitchell, B.G., Siegel, D.A., Carder, K.L., Garver, S.A., Kahru, M. and Mcclain, C., 1998. Ocean color chlorophyll algorithms for SeaWiFS. Journal of Geophysical Research, 103, pp. 24937-24953.

Rezai, H., 1995. Blooms of phytoplankton along the northeastern coast of the Persian Gulf. Iranian Fisheries Research and Training Organization Report, 1, pp. 1-55.

Richlen, M.L., Morton, S. L., Jamali, E. A., Rajan, A., and Anderson, D. M., 2010. The Catastrophic 2008-2009 red tide in the Arabian Gulf region, with observations on the identification and phylogeny of the fish-killing dinoflagellate Cochlodinium Polykrikoides. Harmful algae, 9(2), pp. 163-172.

ROPME, 2003. State of the Marine Environment Report. ROPME Technical Report GC-11/003, Kuwait: Regional Organization for the Protection of the Marine Environment, pp. $1-217$.

Salomonson, V., Guenther, B., and Masuoka, E., 2001. A summary of the status of the EOS Terra Mission Moderate Resolution Imaging Spectroradiometer (MODIS) and attendant data product development after one year of on-orbit performance. In: Proceedings of the International Geoscience and Remote Sensing Symposium, Sydney, Australia, pp. 9-13.

Thangaraja, M., 1998. Report on the incidents of phytoplankton blooms, red tide phenomena, toxic species involved and their impacts in Omani waters. Sultanate of Oman: Ministry of Agriculture and Fisheries, 98(1), p. 52.

Thangaraja, M., Al-Aisry, A. and Al-Kharusi, L., 2007. Harmful algal blooms and their impacts in the middle and outer ROPME sea area. International Journal of Oceans and Oceanography, 2, pp. 85-98.

WDR, 2008. Red tides close desal plants. Water Desalination Report. Houston, TX, 44(1).

Wiggert, J. D., Jones, B. H., Dickey, T. D., Brink, K. H., Weller, R. A., Marra, J., and Codispoti, L. A., 2010. The northeast monsoon's impact on mixing and phytoplankton biomass and nutrient cycling in the Arabian Sea. Deep-Sea Research II, 47, pp. 1353-1385.

Zhao, J., and Ghedira, H., 2014. Monitoring red tide with satellite imagery and numerical models: a case study in the Arabian Gulf. Marine pollution bulletin, 79(1), pp. 305-313.

Zhao, J., Temimi, M., and Ghedira, H. 2015. Characterization of harmful algal blooms (HABs) in the Arabian Gulf and the Sea of Oman using MERIS fluorescence data. ISPRS Journal of Photogrammetry and Remote Sensing, 101, pp. 125-136 